\title{
Research Square \\ Competition for FDI with vintage investment and agglomeration advantages: A revisit
}

Kaushal Kishore ( $\nabla$ kishoreminx@gmail.com )

Indian Institute of Science Education and Research Bhopal

\section{Research Article}

Keywords: Preferential Taxation, Non-preferential Taxation, Dynamic Tax Competition, Tax Holidays

Posted Date: November 5th, 2021

DOI: https://doi.org/10.21203/rs.3.rs-1050030/v1

License: (c) (i) This work is licensed under a Creative Commons Attribution 4.0 International License. Read Full License 


\title{
Competition for FDI with vintage investment and agglomeration advantages: A revisit
}

\author{
kaushal Kishore* \\ Assistant Professor \\ Department of Economic Sciences \\ Indian Institute of Science Education and Research Bhopal \\ Bhopal Bypass Road, Bhauri \\ Madhya Pradesh, India
}

November 4, 2021

\begin{abstract}
We analyze the taxation regimes that may emerge in a two-period dynamic tax competition game where a country that attracts investments during the initial period has agglomeration advantages during the later period. When competing countries choose taxation regimes simultaneously, mixed taxation may arise in an equilibrium where one country adopts a non-preferential and the other adopts a preferential taxation regime. Equilibrium tax revenues of competing countries decrease with the increase in agglomeration effects. Whether a country with a non-preferential or a preferential taxation regime obtains a higher tax revenue depends critically on the extent of agglomeration effects. Moreover, whether a country with a non-preferential or a preferential regime attracts investments during the initial period and in turn will have agglomeration advantages during the later period also depends on the extent of agglomeration effects. When competing countries choose taxation regimes sequentially, a mixed taxation regime arises, and the first mover chooses a non-preferential taxation regime when the agglomeration effect is not very large. On the other hand, when the agglomeration effect is very large, a mixed taxation regime arises where the first mover chooses a preferential and the second mover chooses a non-preferential regime. We provide the complete characterization and proof of the uniqueness of the equilibrium in mixed strategies.
\end{abstract}

JEL classification: F21, H21, H25, H87

Keywords: Preferential Taxation, Non-preferential Taxation, Dynamic Tax Competition, Tax Holidays.

${ }^{*}$ I am extremely thankful to seminar participants at IISER Bhopal for comments and suggestions. All remaining errors are mine. Email: kaushal@iiserb.ac.in Ph: +91 7496088192 


\section{Introduction}

Countries across the world compete to attract footloose foreign capital. Large multinationals often choose their location based on tax rebates offered by different governments ${ }^{1}$. Authors and policymakers argue that increasingly countries are adopting discriminating preferential taxation regimes, where they offer lower tax rates to mobile foreign capital bases and set different (comparatively larger) tax rates on the domestic capital bases. Competition for foreign capital results in very low tax rates on many forms of income, and that in the literature on "tax competition" is termed as the "race to the bottom" effect. Justification against zero tax rates on mobile capital is provided using the agglomeration effect and imperfect capital mobility ${ }^{2}$.

Various measures have been taken through supranational agencies such as OECD to promote cooperation on international taxation and encourage countries to adopt non-preferential taxation regimes ${ }^{3}$. A non-preferential taxation regime discourages countries from setting discriminating (preferential) tax rates based on nationality, mobility, or different vintages of capital. Authors have compared tax revenues under two regimes: (i) non-preferential regime where competing countries jointly adopt non-preferential regime, and (ii) preferential regime where countries are free to set different tax rates ${ }^{4}$. Various authors have found rationals for countries to jointly adopt non-preferential regimes. In particular, Janeba and Peters (1999) show that a country may have an incentive to adopt a non-preferential regime unilaterally under certain conditions. We look at this issue in a dynamic setting when investors are large and their decision affects tax regimes and tax rates. The issue is relevant because a majority of foreign direct investments are made by large multinationals. Moreover, the setting also captures the case when the capital bases are infinitely elastic.

We analyze two questions in this paper: (i) the effect of agglomeration advantage on the competition for foreign capital, and (ii) the kind of taxation regimes that may emerge when countries are free to choose either preferential or non-preferential regimes in the presence of agglomeration effects. There are many papers that compare the tax revenues of competing countries when countries jointly adopt non-preferential or preferential taxation regimes. While many countries have adopted non-preferential taxation regimes ${ }^{5}$, there are many countries that are not willing to do so. Therefore, it is important to understand the nature of the taxation regime that emerges when countries are free to adopt

\footnotetext{
${ }^{1}$ OECD. 1997, Model Tax Convention on Income and on Capital (Paris:OECD Committee on Fiscal Affairs)

${ }^{2}$ For a survey on capital mobility and tax competition, see Zodrow (2021). Other notable papers on capital mobility and tax competition are; Mongrain and Wilson (2018), Haupt and Krieger (2020), Bretschger and Hettich (202), Kishore (2019), Kishore (2018), Hendriks and Nishimura (2021)

${ }^{3}$ See OECD (2004): The OECD's project on harmful tax practices.

${ }^{4}$ See for example; Haupt and Peters (2005), Janeba and Peters (1999), Janeba and Smart (2003), Keen (2001), Wilson (2005), Kishore (2019), etc.

${ }^{5}$ Incentives to adopt non-preferential or preferential taxation regimes may arise in the absence of competition. See for example; Kishore and Roy (2014), Kishore (2017, 2021)
} 
taxation regimes in the presence of agglomeration advantages.

Papers on agglomeration advantage ${ }^{6}$ and tax competition are Borck and Pflüger (2006), Baldwin and Krugman (2004), Konrad and Kovenock (2009), and Kishore (2020). Baldwin and Krugman (2004) show that "a race to the bottom" may not arise with economic integration in the presence of agglomeration forces. Borck and Pflüger (2006) show that when the mobile factor is completely agglomerated in one region then closer integration first results in "race to top" in taxes before leading to "race to the bottom."

The literature on dynamic tax competition is relatively scarce. Notable papers on dynamic tax competition are Konrad and Kovenock (2009), Arcalean (2018), Haupt and Krieger (2020), King, McAfee, and Welling (1993), Kishore (2018, 2021, 2021). Haupt and Krieger (2020) look at the case where countries are involved in subsidy competition during the initial stage, and during the later stage they are involved in tax competition. They find that increasing mobility of firms leads to increasing 'net' tax revenues. Kishore (2018) looks at a similar problem as ours in the absence of agglomeration effects. Kishore (2021) looks at a similar problem in the absence of agglomeration effects where the capital bases that enter during the initial period and the later period are of different sizes. In another paper, Kishore (2021) looks at the case where more than one investor enter the economy during the initial stage. The main focus of the paper is the effect of strategic interaction between large investors during the initial stage on tax competition.

The paper that is most related to ours' is Konrad and Kovenock (2009). In an infinite horizon model where the invested capital depreciates completely and one unit of capital enters the market in each period, Konrad and Kovenock (2009) show that a country is likely to lose the agglomeration advantage. In Konrad and Kovenock (2009), the invested capital is immobile and countries commit to a non-preferential taxation regime during the initial period. A country that has invested capital at the beginning of a period is likely to set a higher tax rate on the foreign capital base. The country without having the domestic capital competes more aggressively and attracts the foreign capital base with a higher probability.

We consider a two-period model where a single investor (owns one unit of capital) enters the market in each period. The capital is fully sunk once invested and the country that attracts the investor during the initial period has agglomeration advantages. In Konrad and Kovenock (2009), during the later period countries compete over two capital bases where one of the capital bases is perfectly immobile, and the cost of relocation of the other capital base is country dependent. The cost of relocation to the country with the agglomeration advantages is zero, and the cost of relocation to the other country is positive. In our paper, the nature of competition during the later period is similar to Konrad and Kovenock (2009). Konrad and Kovenock (2009) look at the competition for foreign capital when competing countries jointly adopt non-

\footnotetext{
${ }^{6}$ See Freret and Maguain (2017) for empirical evidence on the effects of agglomeration on tax competition.
} 
preferential regimes for the entire duration of the game. We allow competing countries to commit to non-preferential or preferential taxation regimes simultaneously (and sequentially) at the beginning of the game. Our result is similar to Konrad and Kovenock (2009), that is, a country is likely to lose agglomeration advantage with a high probability. Moreover, we show that mixed taxation may arise in equilibrium where one country adopts non-preferential taxation while the other adopts a preferential taxation regime. A mixed taxation regime may also arises when countries choose a taxation regime sequentially rather than simultaneously. Whether the country that moves first chooses a preferential or a non-preferential regime depends on the extent of agglomeration effects.

\section{Model}

We consider two identical countries/jurisdictions indexed by $i \in(A, B)$. Economy lasts for two periods, 1 and 2. Countries $(A, B)$ compete to attract investments from outside their jurisdictions. Competing countries have no domestic capital at the beginning of period 1. At the beginning of period 1, a single investor (who owns a unit of capital) enter the market outside of the jurisdictions of competing countries. At the beginning of period 2, an investor with $\beta$ units of capital enters the market outside of the jurisdictions of country $A$ and $B$. For simplicity, we assume that outside the two competing countries, the return on invested capital is equal to 0 . The return on investments in country $A$ and $B$ is equal to 1 in each period. We assume that investments in country $A$ (country $B$ ) are fully sunk. At the beginning of period 1 , there is no cost of relocating to country $A$ or country $B$. At the beginning of period 2 , the cost of relocation to the country that receives investments during the initial period is zero. On the other hand, the cost of relocating to the country that does not receive investments during the initial period is equal to $F$, where $0 \leq F \leq 1$. Konrad and Kovenock (2009) also capture agglomeration advantage in a similar fashion. In other words, the country that receives investments during the initial period has agglomeration advantage in attracting more investments during the later period. We assume that competing countries cannot commit to future tax rates. Therefore, at the beginning of each period, competing countries announce tax rates applicable for that period.

We analyze this dynamic tax competition between two symmetric countries when at the beginning of the game countries simultaneously choose whether to commit to a non-preferential or a preferential regime. If a country commits to a non-preferential taxation regime, it cannot set discriminating tax rates depending on the origin of the capital (domestic and foreign) or capital bases of different vintages (old investments and potential new investments). Under a preferential taxation regime, a country is free to set different tax rates for different capital bases. We assume that governments maximize tax revenues, and investors maximize net returns on investments after-tax payments. We further assume neither governments nor investors discount future income. The stages of the game can be described as below: 
Stage 1: Competing countries simultaneously decide whether to adopt a nonpreferential or a preferential taxation regime for the entire duration of the game. The same is observed by governments and investors. We consider equilibria in pure strategies at this stage of the game. In section (7) we analyze the case when competing countries choose taxation regimes sequentially.

Stage 2: At the beginning of period 1, competing countries simultaneously announce the tax rates applicable in period 1. Even if a country adopts a preferential taxation regime at the initial stage it announces a single tax rate because there is no domestic capital base. The investors observe the prevailing tax rates and taxation regimes, and make an investment in the country $A$ or country $B$.

Stage 3: At the beginning of period 2, competing countries announce tax rates applicable for period 2 . If a country has domestic capital (investments from period 1) and has a preferential taxation regime, then it announces tax rates applicable for the domestic and foreign capital bases. A country announces a single tax rate when it has no domestic capital (no investments during the initial period), or it adopts a non-preferential taxation regime at the initial stage. The new investor observes prevailing tax rates and make an investment in country $A$ or country $B$. Governments receive taxes at the end of period 2 .

We look at the subgame-perfect Nash equilibrium of this three-stage dynamic game.

\section{Non-preferential Regime}

In this section, we look at the case when both countries jointly adopt nonpreferential taxation regimes. First, we look at the outcome in period 2. Without a loss of generality, we assume that country $A$ attracts the investor in period 1.

\subsection{Non-preferential Taxation: Period Two}

Let $t_{a}$ and $t_{b}$ tax rates set by country $A$ and country $B$, respectively. Country $B$ has to undercut the tax rate of country $A$ by a margin of $F$ to attract the mobile investor. The tax revenue of country $A$ in period $2, T N P_{a}^{2}$, can be represented as:

$$
T N P_{a}^{2}= \begin{cases}2 t_{a}, & \text { if } t_{a} \leq t_{b}+F \\ t_{a}, & \text { if } t_{a}>t_{b}+F\end{cases}
$$

When $t_{a} \leq t_{b}+F$, country $A$ attracts the new investor in period 2 as well. When country $A$ sets $t_{a}>t_{b}+F$, country $A$ does not attract the investor in period 2, and it receives taxes only from the domestic capital base. The tax revenue of country $B$ in period $2, T N P_{b}^{2}$, is represented as

$$
T N P_{b}^{2}= \begin{cases}t_{b}, & \text { if } t_{b}<t_{a}-F \\ 0, & \text { if } t_{b} \geq t_{a}-F\end{cases}
$$


When country $B$ undercuts the tax rate of country $A$ by a margin of $F$, it attracts the new investor and receives $t_{b}$. When country sets $t_{b}>t_{a}-F$ then the new investor also invests in country $A$. The tax revenue of country $B$, in this case, is equal to zero.

Lemma 1 When both countries adopt non-preferential taxation regimes during the initial stage of the game and $F>1 / 2$, a pure strategy Nash equilibrium exists. In equilibrium, country $A$ and country $B$ set the tax rates $F$ and 0 , respectively. The equilibrium tax revenues of country $A$ and country $B$ are $2 F$ and 0 , respectively.

When $F<1$, country $B$ can undercut the tax rate of country $A$ by a margin of $F$ to attract the new investor when country $A$ sets a tax rate greater than $F$. In response, country $A$ lowers the tax rate to attract the new investor. Let $t_{a}^{\min }$ be the minimum tax rate country $A$ is willing to set to attract the new investor in period 2. If country set $t_{a}^{\min }$ and attracts the new investor then its tax revenue is equal to $\left(2 t_{a}^{\min }\right)$. Country $A$ can set a tax rate of 1 and extract maximum tax revenue of 1 from the domestic capital base. Therefore, following equality holds: $2 t_{a}^{m i n}=1$. From the equality we have:

$$
t_{a}^{\text {min }}=\frac{1}{2} .
$$

When $F<1 / 2$, country $B$ can undercut the tax rate of country $A$ when country $A$ sets $t_{a}^{\min }$. Therefore, when $F \geq 1 / 2$, country $A$ sets $t_{a}=1-F$ and attracts the new investor. Next, we consider the case when $F<1 / 2$.

Lemma 2 When competing countries jointly adopt non-preferential taxation regimes during the initial stage of the game, a pure strategy Nash equilibrium does not exist when $F<1 / 2$.

Proof. See Appendix.

The argument is simple. Country $A$ lowers the tax rate to attract the new investor as long as the tax rate of country $B$ is large enough. When the tax rate of country $B$ is very low then it is not beneficial for country $A$ to further reduce the tax rate. In this scenario, country $A$ sets the tax rate equal to 1 and receives taxes only from the immobile domestic capital base. Given a pure strategy Nash equilibrium does not exist, we analyze mixed strategy Nash equilibria. Proposition 1 describes the mixed strategy Nash equilibrium when $F<1 / 2$.

Proposition 1 When competing countries jointly adopt non-preferential taxation regimes during the initial stage of the game, a unique mixed strategy Nash equilibrium exists when $F<1 / 2$. The equilibrium tax revenues of country $A$ and country $B$ are 1 and $\left(\frac{1}{2}-F\right)$, respectively. Country $A$ randomizes over the set $\left[\frac{1}{2}, 1\right]$. Country $B$ randomizes over the set $\left[\frac{1}{2}-F, \frac{1}{2}\right)$. The distributions of taxes over the support of country $A, F_{a}$, and country $B, F_{b}$ are $1-\frac{1}{t-F}\left(\frac{1}{2}-F\right)$ and $2-\frac{1}{t+F}$, respectively. There is probability mass of $m_{a}$ at the supremum of 
the support of country $A$, where $m_{a}=\frac{1-2 F}{2(1-F)}$. There is no probability mass over the support of country $B$.

Proof. See Appendix.

The mixed strategy Nash equilibrium described in Lemma 3 has equivalents in the literature. One can think of a Bertrand type competition between two firms where a fraction of consumers is fully loyal to one firm, and a fraction of consumers is partially loyal to the same firm. The other firm has no loyal consumers. This problem is analyzed in Narasimhan (1988). In the literature on tax competition, the equilibrium has similarity with the mixed strategy analyzed in Konrad and Kovenock (2009). We have assumed that country $A$ attracts the investor in period 1 . The probability mass, $m_{a}$, at the supremum of the support of country $A$ decreases when $F$ increases. When $F$ is relatively large, country $B$ more aggressively compete to attract the new investor. In response country $A$ also lowers its tax rate. and The expected tax payments of an investor in period 2 depends on $F_{a}$. Given we know the distribution function, $F_{a}$, the density function, $f_{a}$, is equal to $f_{a} \equiv \frac{1-2 F}{2(t-F)^{2}}$. The expected tax payments in period 2 when the investor invests in country $A$ in period $1, E_{a}$, is equal to $E_{a} \equiv \int_{1 / 2}^{1} t f_{a}(d t)+m_{a}$, where $m_{a}$ is the probability mass at 1 . Substituting for $f_{a}$ and $m_{a}$ we obtain:

$$
E_{a}=\frac{1}{2}+\left(\frac{1}{2}-F\right) \log \left(\frac{1-F}{1-2 F}\right) .
$$

Figure (1) depicts $E_{a}$ as a function of the agglomeration effects, $F$. It is interesting to note that the relation between $F$ and $E_{a}$ is non-monotone. When $F=0$, the competition for the mobile foreign capital is stiff because a country can undercut the tax rate of the competitor by a small margin to attract the mobile investor. When $F$ is in intermediate range, country $A$ is less inclined to lower the tax rate because country $B$ has to undercut its tax rate by a discrete margin. On the other hand, when $F$ is large, country $B$ sets very low tax rate with high probability, prompting country $A$ to lower the tax rate. Note that when $F=\frac{1}{2}$, we have a pure strategy Nash equilibrium where country $A$ sets the tax rate of $\frac{1}{2}$ with probability 1 . This is an important observation, and Lemma 3 describes this observation formally.

Lemma 3 When competing countries jointly adopt non-preferential regimes during the initial stage of the game, the expected tax payment in period 2 of an investor that invests in period 1 is a non-monotone function of the agglomeration effect as long as the agglomeration effect, $F$, is such that, $0 \leq F \leq \frac{1}{2}$. Starting from the no agglomeration effect, the expected tax payment increases with the agglomeration effect, and consequently decreases when the agglomeration effect increases. When $F \geq \frac{1}{2}$, the expected tax payment of the investor is equal to the agglomeration effect, $F$.

Borck and Pflüger (2006) also find that when the capital is fully agglomerated 
in one region then economic integration leads to increase in tax rates before it decreases with economic integration.

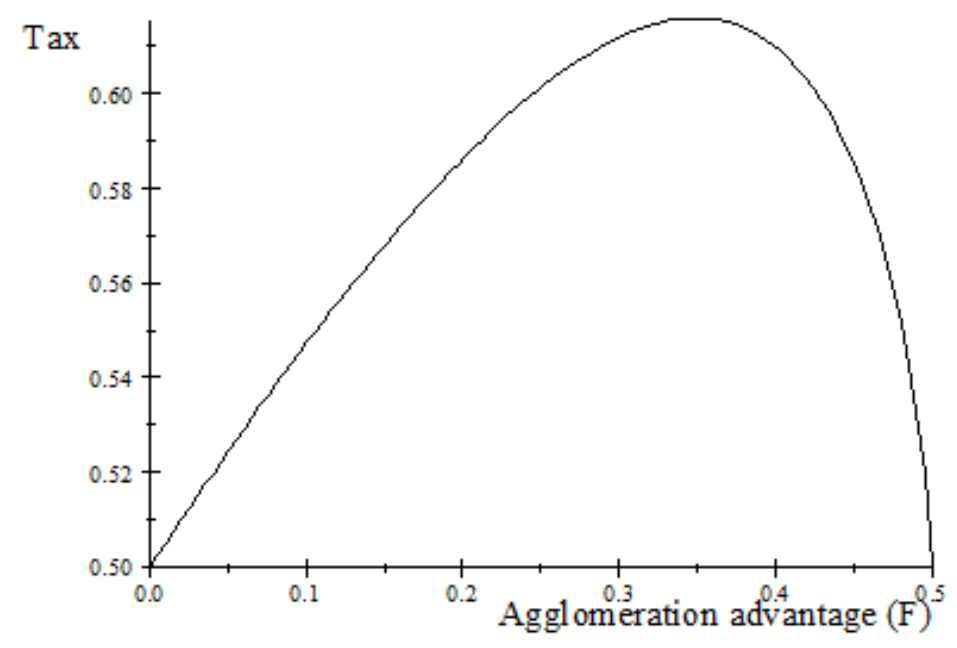

Figure 1: The expected tax payments in period 2 (Tax) for an investor from period 1 as a function of $\mathrm{F}$ (agglomeration advantage)

\subsection{Non-preferential Taxation: Period One}

We know that when a country attracts the investor in period 1 then the tax revenue depends on the agglomeration advantage $F$. The equilibrium tax revenue of country $i$ in period $2, T N P_{i}^{2}$, when it attracts the investor in period 1 is

$$
T N P_{i}^{2}= \begin{cases}2 F, & \text { if } F \geq \frac{1}{2} \\ 1, & \text { if } F \leq \frac{1}{2}\end{cases}
$$

On the other hand, the equilibrium tax revenue of the country that does not attract the investor in period 1 is

$$
T N P_{i}^{2}= \begin{cases}0, & \text { if } F \geq \frac{1}{2} \\ \frac{1}{2}-F, & \text { if } F \leq \frac{1}{2}\end{cases}
$$

The difference in the equilibrium tax revenues of competing countries in period 2 when it attracts the investor in period 1 compared to the case when it does not attract the investor is $2 F$ when $F \geq \frac{1}{2}$. Therefore, the minimum tax rate a country is willing to set in period 1 is equal to $-2 F$ when $F \geq \frac{1}{2}$. The gain in period 2 from attracting the investor in period 1 is completely offset by the tax holidays a country has to offer in period 1 to attract the investor. Therefore, the sum of tax revenues over two periods is equal to 0 when $F \geq \frac{1}{2}$. 
The difference in tax revenues of a country when it attracts the investor in period 1 compared to the case when it does not attract the investor is equal to $\frac{1}{2}+F$ when $F \leq \frac{1}{2}$. Therefore, the minimum tax rate a country is willing to set in period 1 is $-\left(\frac{1}{2}+F\right)$. Therefore, the sum of tax revenues over two periods is equal to $\frac{1}{2}-F$. Lemma 4 describes the outcome in period 1 formally.

Lemma 4 When competing countries jointly adopt non-preferential taxation regimes during the initial stage of the game, the equilibrium tax revenues of competing countries is equal to 0 when $F \geq \frac{1}{2}$. In a unique pure strategy Nash equilibrium, the tax rate in period 1 is equal to $-2 F$. When $F \leq \frac{1}{2}$. the equilibrium tax revenue of competing countries is equal to $\frac{1}{2}-F$. The tax rate in period 1 is equal to $-\left(\frac{1}{2}+F\right)$.

The outcome when $F \leq \frac{1}{2}$ is more interesting. The equilibrium tax revenue increase when $F$ decreases. The tax revenue in period 2 of the country that attracts the investor in period 1 does not depend on the extent of the agglomeration effect. On the other hand, the tax revenue in period 2 of the country that does not attract the investor in period 1 decreases when the agglomeration effect increases. This leads to increase in competition to attract the investor in period 1. This is evident from the fact that the tax holidays on offer in period 1 increases when the extent of the agglomeration effect increases. In the next section we look at the outcome under a mixed taxation regime, i.e., when one country adopts a non-preferential taxation regime, and the other adopts a preferential taxation regime.

\section{Mixed Taxation Regime}

Without loss of generality suppose country $A$ adopts a non-preferential, and country $B$ adopts a preferential taxation regime. First, we look at the outcome in period 2.

\subsection{Mixed Taxation Regime: Period Two}

The outcomes in period 2 depend on whether country $A$ or country $B$ attracts the investor in period 1 . When country $A$ attracts the investor in period 1 then the outcomes in period 2 are described by Lemmas 1-2, and Proposition 1. Now suppose country $B$ attracts the investor in period 1 . Country $B$ sets different tax rates on the immobile domestic capital base, and the mobile foreign capital base. Therefore, country $B$ sets the tax rate of 1 on the domestic capital base, and receives a tax revenue of 1 . Country $A$ has to undercut the tax rate of country $B$ by a margin of $F$ to attract the new investor. Therefore, country $B$ sets a tax rate of $F$ on the foreign capital base, and receives a tax revenue of $F$. Country $A$ sets a tax rate of 0 on the foreign capital base. Lemma 5 describes the outcome formally. 
Lemma 5 When country $A$ adopts a non-preferential and country $B$ adopts a preferential taxation regime, and country $B$ attracts the investor in period 1 , the equilibrium tax revenues of country $A$ and country $B$ are 0 and $1+F$, respectively. Country $A$ sets a tax rate of 0 on the foreign capital base. Country $B$ sets 1 and $F$, respectively on the domestic and the foreign capital base.

The proof is obvious from the above discussion. Next we look at the outcome in period 1.

\subsection{Mixed Taxation Regime: Period One}

First, we analyze the outcome in period 1 when $F \geq \frac{1}{2}$. The tax revenues of country $A$ and country $B$ are $2 F$ and 0 , respectively in period 2 when country $A$ attracts the investor in period 1. On the other hand, the tax revenues of country $A$ and country $B$ are 0 and $1+F$ respectively, when country $B$ attracts the investor in period 1 . The revenue gains to country $A$ and country $B$ in period 2 from attracting the investor in period 1 are $2 F$ and $1+F$, respectively. Moreover, if an investor invests in country $A$ in period 1 , the tax it pays in period 2 is $F$. On the other hand, if an investor invests in country $B$ then the tax it pays in period 2 is 1 . Therefore, country $B$ has to undercut the tax rate of country $A$ by a margin of $1-F$ to attract the investor. The minimum tax rate country $A$ is willing to set to attract the investor in period 1 is $-2 F$. Therefore, the tax rate country $B$ has to set to attract the investor is $-2 F-(1-F) \equiv-(1+F)$. Therefore, country $A$ and country $B$ set the tax rates $-2 F$ and $-(1+F)$, respectively in period 1 . Irrespective of whether the investor invests in country $A$ or country $B$, the gains to competing countries in period 2 are completely offset by tax rebates they offer in period 1.

Lemma 6 In a scenario where country $A$ adopts a non-preferential and country $B$ adopts a preferential taxation regime during the initial stage of the game, the sum of the tax revenues over two periods in equilibrium is equal to 0 when $F \geq \frac{1}{2}$. Country $A$ and country $B$ set $-2 F$ and $-(1+F)$, respectively in period 1. The investor is indifferent between making an investment in country $A$ or country $B$.

The proof is obvious from the above discussion. Now we look at the outcomes when $F \leq \frac{1}{2}$. When country $A$ attracts the investor in period 1, the outcome of period 2 is described in Proposition 1. The equilibrium tax revenues of country $A$ and country $B$ are 1 and $\left(\frac{1}{2}-F\right)$, respectively. When country $B$ attracts the investor in period 1 then the outcome of period 2 is described in lemma 5 . The equilibrium tax revenues of country $A$ and country $B$ are 0 and $(1+F)$, respectively. Therefore, the revenue gains to country $A$ and country $B$ in period 2 from attracting the investor in period 1 are 1 and $\left(\frac{1}{2}+2 F\right)$, respectively. Note that the revenue gain to country $A$ is larger compared to that of country $B$ when $F \leq \frac{1}{4}$. Moreover, if an investor invests in country $A$ in period 1 , it pays $E_{a}$ in taxes in period 2, where $E_{a}$ is given by (4). Therefore, country $B$ has to 
undercut the tax rate of country $A$ by a margin of $1-E_{a}$ to attract the investor in period 1. The maximum tax rebates country $A$ and country $B$ are willing to offer in period 1 are 1 and $\left(2 F+\frac{1}{2}\right)$, respectively. Therefore, country $A$ attracts the investor when $1+1-E_{a}>2 F+\frac{1}{2}$, and country $B$ attracts the investor when $1+1-E_{a}<2 F+\frac{1}{2}$. Let $F_{\max }$ be the value of $F$ such that $^{7}$

$$
\text { Dif } \equiv E_{a}+2 F-\frac{3}{2}=0 \text {. }
$$

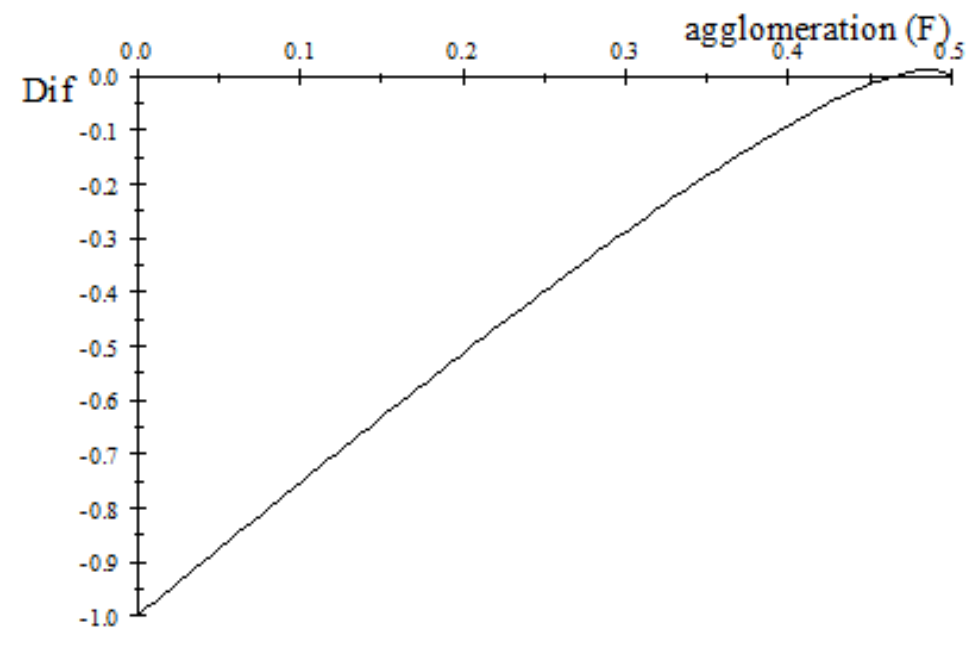

Figure 2: The function "Dif" as a function of F (agglomeration advantage)

From figure (2), it is clear that Dif $>0$ for $F$ is close to $\frac{1}{2}$. Now we consider two different scenarios: (i) $F \leq F_{\max }$, (ii) $F \geq F_{\max }$.

When $F \leq F_{\max }$, country $A$ attracts the investor in period 1. Country $A$ offers a tax holiday of amount $T_{h}^{a}$ in period 1 and attracts the investor in period 1 , where

$$
T_{h}^{a} \equiv 2 F+\frac{1}{2}-\left(1-E_{a}\right) \equiv 2 F+E_{a}-\frac{1}{2}
$$

The equilibrium tax revenue of country $A, T M_{a}$, is equal to

$$
T M_{a}=1-T_{h}^{a}=\frac{3}{2}-2 F-E_{a} .
$$

The equilibrium tax revenue of country $B, T M_{b}$, is equal to $\frac{1}{2}-F$. From (7) and (9), it is evident that country $A$ attracts the investor as long as the gain from attracting the investor in period 1 is positive. Let $F^{*}$ be such that

\footnotetext{
${ }^{7}$ We do not solve for the exact value of $F$. The numerical approximation of $F$ is approximately 0.464
} 


$$
T M_{a}=\frac{1}{2}-F
$$

, that is, the tax revenues of country $A$ and country $B$ are equal ${ }^{8}$. When $F \in\left(0, F^{*}\right)$, country $A$ receives a higher tax revenue compared to that of country $B$. When $F \in\left(F^{*}, F_{\max }\right)$, country $B$ receives a higher tax revenue. Lemma 7 describes the outcomes formally.

Lemma 7 In a mixed taxation regime where country $A$ adopts a nonpreferential taxation regime, and country $B$ adopts a preferential taxation regime, the equilibrium tax revenues of country $A$ and country $B$ are $T M_{a}$ and $\frac{1}{2}-F$, respectively when $F \leq F_{\max }<\frac{1}{2}$. Country $A$ offers a tax rebate of $T_{h}^{a}$ in period 1 and attracts the investor. When $0 \leq F \leq F^{*}$ country $A$ earns a higher tax revenue compared to country $B$. On the other hand, the equilibrium tax revenue of country $B$ is higher when $F^{*} \leq F \leq F_{\max } . T M_{a}$ and $T_{h}^{a}$ are given by (9) and (8). The parameters $F_{\max }$ and $F^{*}$ are solutions of (7) and (10), respectively.

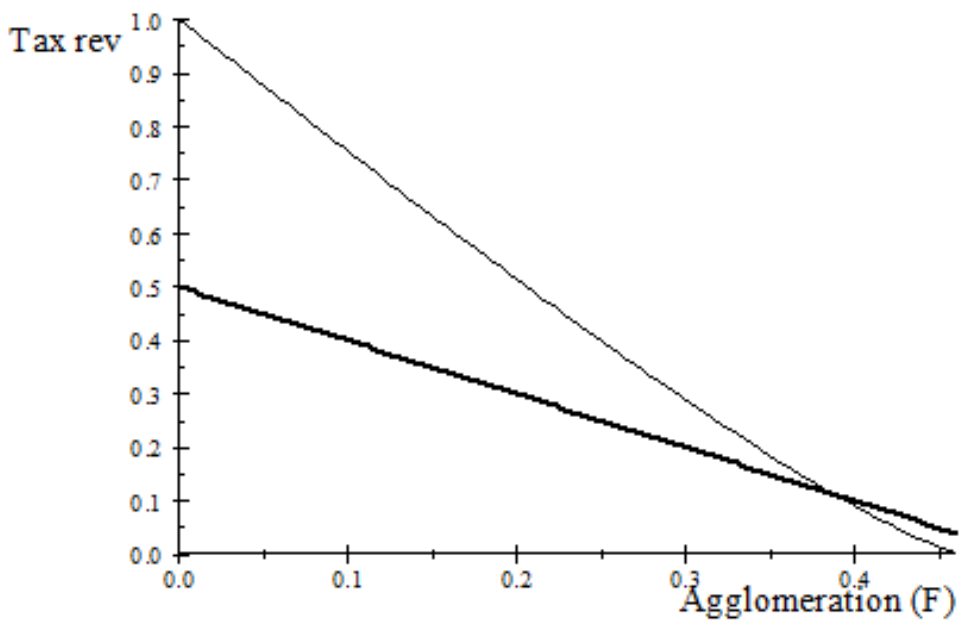

Figure 3: The tax revenues of country $A$ (thin line) and country $B$ as a function of $F$ (agglomeration advantage) under a mixed taxation regime when

$$
F \leq F_{\max }
$$

Figure 3 depicts the equilibrium tax revenues of country $A$ and country $B$. The tax revenues of competing countries decrease when the agglomeration advantage increases as long as $F \leq F_{\max }$. It is worth taking note of the fact that for a reasonable range of values of $F \in\left(F^{*}, F_{\max }\right)$, the tax revenue of the country that does not attract the investor in period 1 is higher. If country $A$ does not attract the investor in period 1 , it does not receive a positive tax revenue

${ }^{8}$ approximate value is 0.387 
in period 2. Therefore, country $A$ is willing offer tax rebates in period 1 as long as the revenue gain from doing so is strictly positive. Moreover, the tax rebate country $B$ is willing to offer increases when $F$ increases. Therefore, the tax rebate country $A$ has to offer in period 1 increases when $F$ increases. This reduces the equilibrium tax revenue of country $A$. This may explain why United States (USA) follows a preferential taxation regime even though most countries in European Union (EU) follow non-preferential taxation regimes.

When $F \geq F_{\max }$, country $B$ (with a preferential taxation) attracts the investor in period 1 . Country $B$ undercuts the minimum tax rate country $A$ offers in period 1 by a margin of $\left(1-E_{a}\right)$ and attracts the investor, where $E_{a}$ is given by (4). As discussed before, the minimum tax rate country $A$ is willing to set in period 1 is -1 . Therefore, country $B$ sets a tax rate of $-1-\left(1-E_{a}\right) \equiv-2+E_{a}$ in period 1 . The sum of tax revenues of country $B$ over two periods is $1+F-2+E_{a} \equiv F+E_{a}-1$. Lemma 8 describes the outcome formally.

Lemma 8 In a scenario where country $A$ adopts a non-preferential and country $B$ adopts a preferential taxation regime during the initial stage of the game, the equilibrium tax revenues of country $A$ and country $B$ are 0 and $F+E_{a}-1$, respectively. Country $B$ offers a tax rebate of $2-E_{a}$ in period 1 and attracts the investor, where $E_{a}$ is given by (4).

The equilibrium tax revenue of country $A$ when it attracts the investor and when it does not attract the investor are equal when $F+E_{a}-1=\frac{1}{2}-F$, or equivalently $2 F+E_{a}-\frac{3}{2}=0$. Equation (7) that determine the critical value of $F$ is also same. Therefore, the tax revenue of country $B$ is continuous. I do not show it algebraically, but the graphical and numerical observations reveal that for $F \in\left(F_{\max }, \frac{1}{2}\right), E_{a}$ is a decreasing function of $F$. Numerical observation also reveals that the equilibrium tax revenue of country $B$ decreases when $F$ increases ${ }^{9}$.

In the next section we analyze the outcomes when both countries jointly adopt preferential taxation regimes, i.e., both countries set different tax rates on the immobile domestic capital base, and the mobile foreign capital base.

\section{Preferential Taxation}

The outcome under the preferential taxation regime is straightforward, and we omit the detailed discussion. The country that attracts the investor in period 1 receives 1 and $F$ in taxes from the domestic and the foreign capital base, respectively. The tax revenue of the country in period 2 that does not attract the investor is period 1 is equal to 0 . Therefore, the minimum tax rate a country sets in period 1 to attract the investor is equal to $1+F$. The revenue gain in period 2 is complete offset by the tax rebate a country has to offer in period

\footnotetext{
${ }^{9}$ Numerical observation shows that $\frac{d\left(F+E_{a}-1\right)}{d F}=-1.2351$ for $F=0.47$
} 
1 to attract the investor. Therefore, the equilibrium tax revenue of competing countries is equal to 0 . Lemma 9 describes the outcome formally.

Lemma 9 When both countries adopt preferential taxation regime during the initial stage of the game, the equilibrium tax revenue of competing countries is equal to 0 . The tax rate in period 1 is equal to $-(1+F)$. The country that attracts the investor in period 1 sets the tax rates of 1 and $F$, respectively on the domestic and the foreign capital base. The country that does not receive investments in period 1 sets the tax rate of 0 on the foreign capital base.

\section{Comparison}

From Lemma 4, we know that the tax revenue of competing countries is equal to zero when both countries jointly adopt non-preferential taxation and $F \geq \frac{1}{2}$. The same is also true under mixed taxation and preferential taxation regimes when $F \geq \frac{1}{2}$. Next, we look at the more interesting case when $F \leq \frac{1}{2}$. The outcomes of the game under different choices of taxation regimes are described in the table below.

$$
\begin{array}{ccc} 
& \text { Non-preferential } & \text { Preferential } \\
\text { Non-preferential } & \left(\frac{1}{2}-F, \frac{1}{2}-F\right) & \left(T M_{a}, \frac{1}{2}-F\right) \\
\text { Preferential } & \left(\frac{1}{2}-F, T M_{a}\right) & (0,0)
\end{array}
$$

$T M_{a}$ is given by (9). We know that $T M_{a} \geq \frac{1}{2}-F$ when $F \leq F^{*}$, and $T M_{a} \leq \frac{1}{2}-F$ when $F \geq F^{*}$, where $F^{*}$ is described by (10). Non-preferential taxation and mixed taxation regimes are subgame-perfect equilibria of the game. Starting from a scenario where both countries have preferential taxation regime, a country has an incentive to deviate and adopt a non-preferential taxation regime. Starting from a scenario where both countries have non-preferential regimes, a country has an incentive to convince the other country to adopt a preferential taxation regime when the agglomeration effect is not very large, i.e., $F \leq F^{*}$. On the other hand, starting from a scenario where both countries have non-preferential regimes, a country is worse off if the other country deviates and adopts a preferential regime when the agglomeration effect is considerably large, i.e., $F \geq F^{*}$. Proposition describes the comparison between taxation regimes formally.

Proposition 2 Non-preferential taxation regime or mixed taxation regime are two subgame-perfect equilibria of the game. The tax revenue of the country that adopts a preferential taxation regime in a mixed taxation regime is equal to that a country earns when both countries adopt non-preferential taxation regimes. Under a mixed taxation regime, the tax revenue of the country with a non-preferential regime is greater than the country with a preferential taxation regime when $0<F \leq F^{*}$. The opposite is true when $F^{*} \leq F \leq \frac{1}{2}$. The 
equilibrium tax revenue is equal to 0 under each taxation regime when $F \geq \frac{1}{2}$.

We can relate the outcomes with present policy discussion on preferential and non-preferential taxation regimes. Most countries in European Union (EU) have non-preferential regimes. On the other hand, Unites States (USA) has been following preferential taxation regimes but the latest update is that USA is also committed to abolish preferential taxation regime ${ }^{10}$. The outcome predicts that if the agglomeration effect is large enough, EU has an incentive to convince USA to adopt a non-preferential regime. If agglomeration effect were not substantial, EU would be better if USA continues to follow preferential taxation regime. The model predicts that USA is indifferent between having a non-preferential or a preferential regime. The outcomes also hint that the stability of taxation regimes is not guaranteed.

\section{Discussion: Sequential Model}

Now we analyze the outcomes when countries choose taxation regimes sequentially rather than simultaneously. First, we analyze the case when $F \leq F^{*}$. Without loss of generality suppose country $A$ is the first mover. If country $A$ chooses a non-preferential taxation regime, then country $B$ is indifferent between choosing a non-preferential and a preferential taxation regime. Let's assume that when a country is indifferent between two taxation regimes, it chooses a non-preferential and a preferential taxation regime with probability $P$ and $1-P$, respectively. Therefore, the tax revenue of the first mover when it chooses a non-preferential taxation regime is, $P\left(\frac{1}{2}-F\right)+(1-P) T M_{a}$. Now suppose country $A$ chooses a preferential taxation regime. Country $B$ receives $T M_{a}$ and $\frac{1}{2}-F$, respectively when it chooses a non-preferential and a preferential taxation regime. When $F \leq F^{*}, T M_{a} \geq \frac{1}{2}-F$. Therefore, country $B$ chooses a non-preferential taxation regime. Therefore, the tax revenue of country $A$ is $\frac{1}{2}-F$. Note that $P\left(\frac{1}{2}-F\right)+(1-P) T M_{a} \geq \frac{1}{2}-F$ when $F \leq F^{*}$. Therefore, country $A$ (the first mover) chooses a non-preferential taxation regime. The outcome is formally described in Proposition .

Proposition 3 When countries choose taxation regimes sequentially and $F \leq F^{*}$, a mixed taxation regime arises. The first mover chooses a nonpreferential regime, and the second mover chooses a preferential taxation regime.

Now we analyze the case when $F^{*} \leq F \leq \frac{1}{2}$. As before we assume country $A$ is the first mover. Suppose country $A$ chooses a non-preferential taxation regime. Irrespective of the taxation regime chosen by country $B$, it receives $\frac{1}{2}-F$ in tax revenues. Suppose country randomizes over a non-preferential and a preferential

\footnotetext{
${ }^{10}$ See the table that presents the new results on preferential regimes from the FHTP meeting in April 2021. The report can be accessed at "https://www.oecd.org/tax/beps/harmful-taxpractices-peer-review-results-on-preferential-regimes.pdf"
} 
taxation regime with probabilities $P$ and $(1-P)$, respectively. Therefore, country $A$ receives tax revenues of $\frac{1}{2}-F$ and $T M_{a}$ with probabilities $P$ and $(1-P)$, respectively. Therefore, the tax revenue of country $A$ is $P\left(\frac{1}{2}-F\right)+(1-P) T M_{a}$. Note that $\frac{1}{2}-F \geq P\left(\frac{1}{2}-F\right)+(1-P) T M_{a}$ when $P>0$ and $F^{*} \leq F \leq \frac{1}{2}$. Therefore, a mixed taxation regime arises where country $A$ chooses a preferential, and country $B$ chooses a non-preferential taxation regime. Proposition 4 describes the outcome formally.

Proposition 4 When countries choose taxation regimes sequentially and $F^{*} \leq F \leq \frac{1}{2}$, a mixed taxation regime arises. The first mover chooses a preferential regime, and the second mover chooses a non-preferential taxation regime.

\section{Conclusion}

The paper answers a pressing question of whether a country has an incentive to adopt a non-preferential taxation regime even when the competitor continues to adopt a preferential taxation in the presence of agglomeration effect. We show that a country is better off having a non-preferential taxation regime when the other country has a preferential regime. Moreover, the country with a non-preferential taxation has no incentive to convince the other country to co-ordinate and jointly adopt non-preferential taxation regimes as long as the agglomeration effect is not very large. When the agglomeration effect is very large, the country with a non-preferential taxation regime has an incentive to convince the other country to adopt non-preferential taxation regime. In this case, the country is not worse off from adopting a non-preferential taxation regime. We also show that the tax revenues of competing countries decrease when the agglomeration effect increase. In the later period of the game, the country without the agglomeration advantage attracts investments with a positive probability. Therefore, a country can lose the agglomeration advantage. This observation is in line with the result in Konrad and Kovenock (2009). Our results are likely to hold in the infinite periods model as well.

Moreover, we also analyze the game when competing countries choose taxation regimes sequentially rather than simultaneously. We show that a mixed arises in the equilibrium. When the agglomeration effect is not very large, the first mover chooses a non-preferential taxation, and the second mover chooses a preferential taxation regime. The tax revenue of the first mover is strictly higher than the second mover. When the agglomeration effect is very large, the first mover chooses a preferential taxation regime, and the second mover chooses a non-preferential taxation regime. The tax revenue of the first mover is strictly larger than the second mover.

Under non-preferential taxation regime, the expected tax payment of an investor that invested during the initial period is a non-monotone function of the agglomeration effect. Starting from no agglomeration effects, the expected tax payment increases with agglomeration effect before decreasing when the 
agglomeration effect is significantly large. The equilibrium tax revenues of competing countries is also a decreasing function of the agglomeration effect. This suggests that having agglomeration effect may not be beneficial when it comes to collecting tax revenues.

\section{References}

[1] Arcalean, C., 2018. Dynamic fiscal competition: A political economy theory. Journal of Public Economics, 164, 211-224.

[2] Haupt, A., Krieger, T., 2020. The role of relocation in tax and subsidy competition. Journal of Urban Economics, 116.

[3] Baldwin, E., and Krugman, P., 2004. Agglomeration, integration and tax harmonisation. European Economic Review, 48, 1-23.

[4] Bretschger, L., Hettich, F., 2002. Globalisation, capital mobility and tax competition: theory and evidence for OECD countries, 18, 695-716.

[5] Borck, R., Pflüger, M., 2006, Agglomeration and Tax Competition. European Economic Review, 50, 647-668.

[6] Haupt, A., Peters, W., 2005. Restricting preferential tax regimes to avoid harmful tax competition. Regional Science and Urban Economics, 35, 493507.

[7] Haupt, A., Krieger, T., 2020. The role of relocation mobility in tax and subsidy competition. Journal of Urban Economics, 116, 103196.

[8] Hindriks, J., Nishimura, Y., 2021. Taxing multinationals: The scope for enforcement cooperation. Journal of Public Economic Theory, 23, 487-509.

[9] Janeba, E., Peters, W., 1999. Tax evasion, tax competition and the gains from non-discrimination: The case of interest taxation in Europe. Economic Journal, 109, 93-101.

[10] Janeba, E., Smart, M., 2003. Is targeted tax competition less harmful than its remedies? International Tax and Public Finance, 10, 259-280.

[11] Keen, M., 2001. Preferential regimes can make tax competition less harmful. National Tax Journal, 54, 757-762.

[12] Konrad, Kai A., and Kovenock, D., 2009, Competition for FDI with vintage investment and agglomeration advantages. Journal of international Economics, 79, 230-237.

[13] Kishore, K., 2018. Dynamic Tax Competition, Home Bias and the gain from Non-preferential Taxation Regimes: A case for unilateral commitment. working paper. 
[14] Kishore, K., 2021. Falling cost of capital relocation and preferential taxation of foreign capital. working paper.

[15] Kishore, K., 2021. Dynamic tax competition between symmetric countries with multiple strategic investors. working paper.

[16] Kishore, K., 2021. Tax Competition between Symmetric countries for Large Asymmetric Investors. working paper.

[17] Kishore, K., 2014. Dynamic Inconsistency and non-preferential taxation of foreign capital. Economics Letters, 124, 88-92.

[18] Kishore, K., 2017. Dynamic Inconsistency and preferential taxation of foreign capital. International Tax and Public Finance, 24, 381-396.

[19] Kishore, K., 2019. Tax Competition, Imperfect Capital Mobility, and the gain from non-preferential agreements. The Journal of International Trade and Economic Development, 28, 755-774.

[20] King, I., McAfee, P., Welling, L., 1993. Industrial Blackmail: Dynamic Tax Competition and Public Investment. The Canadian Journal of Economics, 26, 590-608.

[21] Mongrain, S., Wilson, J., 2018. Tax competition with heterogeneous capital mobility. Journal of Public Economics, 167, 177-189.

[22] Narasimhan, C., 1988, Competitive promotional strategies. Journal of business $61,427-449$.

[23] Freret, S., Maguain, D., 2017, The effects of agglomeration on tax competition: evidence from a two-regime spatial panel model on French data. International Tax and Public Finance, 24, 1100-1140.

[24] OECD. 1997, Model Tax Convention on Income and on Capital (Paris: OECD Committee on Fiscal Affairs).

[25] Organization for Economic Cooperation and Development (2004). The OECD's project on harmful tax practices, Paris: OECD

[26] Wilson, J., 2005. Tax competition with and without preferential treatment of a highly mobile tax base, in The challenges of Tax Reform in a Global Economy, edited by James Alm, Jorge Martinez-Vazquez, and Mark Rides, Springer.

[27] Zodrow, G., 2010. Capital Mobility and Capital Tax Competition. National Tax Journal, 63, 865-901. 


\section{Appendix}

Proof of Lemma 2. Suppose the tax pair $\left(t_{a}, t_{b}\right)$ is a Nash equilibrium such that $t_{a}<F$. The maximum possible tax revenue of country $A$ for a tax pair $\left(t_{a}, t_{b}\right)$ is equal to $2 F$, that is strictly less than 1 . Country $A$ can set $t_{a}=1$ and obtain a tax revenue of 1 . Contradicting that we have a Nash equilibrium. Similarly, suppose that the tax pair $\left(t_{a}, t_{b}\right)$ is a Nash equilibrium such that $F<t_{a}<1$. The best response of country $B$ is to undercut the tax rate of country $A$ by a margin of $F$. Therefore, the maximum possible tax revenue is $t_{a}$. Because $t_{a}<1$, country $A$ does better when it sets $t_{a}=1$. Only possible Nash equilibrium is the strategy pair $\left(1, t_{b}\right)$, where country $A$ sets $t_{a}=1$. When $t_{a}=1$, the best response of country $B$ is $1-F$. Because $F<\frac{1}{2}$, we have $1-F>\frac{1}{2}$. Country $A$ does better when it sets a tax rate arbitrary close to $1-F$. Contradicting that we have a Nash equilibrium. This proves that a Nash equilibrium in pure strategies does not exist. $Q E D$.

Proof of Proposition 1. First, we show that the strategies pair $\left(F_{a}, F_{b}\right)$ described in Lemma 3 is a mixed strategy Nash equilibrium of the game. Note that the supremum of the support of country $A$ is equal to 1 , that is also the maximum tax rate a country can set. Therefore, country $A$ cannot set a tax rate greater than 1 and do better. Country $A$ can set the tax rate equal to 1 and obtain a tax revenue of 1 with certainty. If country $A$ sets a tax rate, $t_{a}$, lower than $\frac{1}{2}$ and attract the new investor with certainty, its tax revenue is $2 t_{a}$, that is lower than 1 when $F \leq \frac{1}{2}$. Therefore, country $A$ cannot deviate and do better. Similarly, we can show that country $B$ cannot do better from a unilateral deviation.

Now we follow Narasimhan (1988) to prove the uniqueness of the mixed strategy Nash equilibrium. Let $S_{a}^{*}$ and $T_{b}^{*}$ be equilibrium strategy sets of country $A$ and country $B$ described in Lemma 3 . Define the strategy set $S_{b}^{*}$ such that $S_{b}^{*} \equiv T_{b}^{*}+F$. Now, we prove Lemma 3 in steps $1-4$.

Step 1. The equilibrium strategy sets $S_{a}^{*}$ and $T_{b}^{*}$ are convex, or equivalently strategy sets $S_{a}^{*}$ and $S_{b}^{*}$ are convex.

Proof. Note that when $S_{b}^{*}$ is convex then $T_{b}^{*}$ is also convex.

First, we show that $T=S_{a}^{*} \cap S_{b}^{*}$ is convex. Let $\hat{T}=\inf (T)$ and $\hat{\hat{T}}=\sup (T)$. We show that there is no hole in $T$, that is, there is no interval $I=\left(T^{k}, T^{h}\right)$ such that, for $\hat{T}<T^{k}<T^{h}<\hat{\hat{T}}$ and for $t \in I, t \notin T$. This can happen when one of the countries have the support over $T$ and the other does not, or neither countries has support over the interval $I$.

First, we show that if country $A$ sets $t_{a} \in I$ with probability zero then so does country $B$. Let $t^{1}$ and $t^{2}$ be defined as 


$$
\begin{array}{r}
t^{1} \in S_{a}^{*} \text { and } t^{1}=\sup \left(T \mid T<T^{k}\right) \\
t^{2} \in S_{a}^{*} \text { and } t^{2}=\inf \left(T \mid T>T^{k}\right) \\
t_{b}^{1}=t^{1}-F \\
t_{b}^{2}=t^{2}-F
\end{array}
$$

Now define Suppose country $B$ sets a tax rate $t_{b} \in I$, this is equivalent to country $B$ setting a tax rate $t_{b}-F \in I-F$. Therefore, the tax revenue of country $B$ in period 2 is $t_{b}\left(1-F_{a}\left(t_{b}+F\right)\right)$ is increasing in $t_{b}$ for $t_{b}-F \in I-F$. Therefore, country $B$ is better off shifting the probability mass to $t^{1}$.

Now consider the case when neither country is randomizing over the set $I$. In this case country $B$ is better off setting $t_{b}=t_{b}^{2}$ compared to $t_{b}=t_{b}^{1}$. The reason is that $t_{b}^{2}>t_{b}^{1}$, and at the same time country $A$ is not randomizing over the set. Therefore, the probability that country $B$ undercuts the tax rate of country $A$ does not change. Similarly, we can show that there is no hole in $T^{\prime}=S_{i}^{*}-S_{i}^{*} \cap S_{j}^{*}$.

This proves that $S_{a}^{*}$ and $S_{b}^{*}$ are convex. When $S_{b}^{*}$ is convex, $T_{b}^{*}$ is also convex.

Step 2. Neither country can have a mass point anywhere other than the supremum of its support. Moreover, only one of the countries can have a mass point at the supremum of its support.

Proof. First, we show that country $A$ cannot have a mass point at the interior of its support. Let $\hat{T}_{a}=\inf \left(S_{a}^{*}\right)$ and $\hat{\hat{T}}_{a}=\sup \left(S_{a}^{*}\right)$. Suppose country $A$ sets $t_{a}^{*}$ with a probability mass of $m$, where $\hat{T}_{a}<t_{a}^{*}<\hat{\hat{T}}_{a}$. Note that when $t_{a}^{*}$ lies in the interior of country $A$ 's support, then $t_{a}^{*}-F$ should lie in the interior of country $B$ 's support. This is evident from step 1 . When $t_{a}^{*}-F$ lies in the interior of country $A$ 's support then $t_{a}^{*}-F+\epsilon$ and $t_{a}^{*}-F-\epsilon$ are also in the interior of country $B$ 's support. The tax revenue of country $B$ when it sets $t_{b}=t_{a}^{*}-F+\epsilon$ is

$$
\left(t_{a}^{*}-F+\epsilon\right)\left(1-F_{a}\left(t_{a}^{*}+\epsilon\right)\right)
$$

The tax revenue of country $B$ when it sets $t_{b}=t_{a}^{*}-F-\epsilon$ is

$$
\left(t_{a}^{*}-F-\epsilon\right)\left(1-F_{a}\left(t_{a}^{*}-\epsilon\right)\right)
$$

Subtracting (11) from (12) we obtain

$$
2 \epsilon-\epsilon\left(F_{a}\left(t_{a}^{*}+\epsilon\right)-F_{a}\left(t_{a}^{*}-\epsilon\right)\right)+\left(t_{a}^{*}-F\right)\left(\left(F_{a}\left(t_{a}^{*}+\epsilon\right)-F_{a}\left(t_{a}^{*}-\epsilon\right)\right)\right)
$$

The same can be simplified to

$$
2 \epsilon-\epsilon m+\left(t_{a}^{*}-F\right) m
$$


The value described above is greater than 0 for arbitrarily small $\epsilon$. Therefore, country $B$ can do better. This contradicts that we have a mixed strategy Nash equilibrium. Similarly, we can show that country $B$ cannot have a mass point at the interior of its support.

Step 3. The strategy sets $S_{a}^{*}$ and $S_{b}^{*} \equiv T_{b}^{*}+F$ are identical when neither country has a mass point, where $S_{a}^{*}$ and $T_{b}^{*}$ are equilibrium strategy sets of country $A$ and country $B$, respectively. When country $A$ has a mass point at $\hat{T} \equiv \sup \left(S_{a}^{*}\right)$ of its support, country $B$ sets $\hat{T}-F$ with zero probability.

Proof. First, consider the case of no mass point. Assume to the contrary that $S_{b}^{*} \subset S_{a}^{*}$. We know from earlier discussion that interval where country $B$ has no support will either be on the upper or the lower end. Suppose it lies to the upper end. Define $\hat{\hat{A}}=\sup \left(S_{a}^{*}\right)$, and $\hat{A}=\sup \left(S_{b}^{*}\right)$. Country $A$ can move probability mass from the set $(\hat{\hat{A}}, \hat{A})$ to $\hat{\hat{A}}$ and do strictly better. This contradicts that we have a mixed strategy Nash equilibrium. Similarly, we can show a contradiction when country $B$ does not have support to the lower end of country $A$ 's support. step 4. $\sup \left(S_{a}^{*}\right)=1$ and $\sup \left(T_{a}^{*}\right)=1-F$.

Proof. It is easy to argue that $\sup \left(S_{a}^{*}\right)=1$. Suppose to the contrary that $\sup \left(S_{a}^{*}\right)=s$, where $s<1$. When country $A$ sets $s$, country $B$ undercuts the tax rate of country $A$ with probability 1 . Therefore, the equilibrium tax revenue of country $A$ is $s$, that is strictly less than 1 . This is a contradiction. From step 3, we know that $\sup \left(S_{a}^{*}\right)=\sup \left(T_{b}^{*}+F\right)$. Therefore, $\sup \left(T_{b}^{*}\right)=1-F$. Hence, proved. QED. 